\title{
Familial visceral myopathy associated with a mitochondrial myopathy
}

\author{
R Lowsky, G Davidson, S Wolman, K N Jeejeebhoy, R A Hegele
}

\begin{abstract}
A 27 year old man with intestinal pseudoobstruction who developed parenteral nutrition induced hyperlipidaemia and who also had ophthalmoplegia and an undifferentiated myopathy is described. Histological examination of biopsy specimens and molecular analysis show that this patient had both familial visceral myopathy and a mitochondrial myopathy, suggesting that a mitochondrial DNA mutation is the molecular lesion in familial visceral myopathy.

(Gut 1993; 34: 279-283)
\end{abstract}

The familial visceral myopathy syndromes are a clinically heterogeneous group of rare disorders of unknown molecular origin. Segregation patterns consistent with both autosomal dominant and autosomal recessive inheritance have been described in affected kindreds.' The hallmark of the syndromes is the histological intestinal abnormality characterised by smooth muscle cell vacuolar degeneration, loss, and fibrosis, especially of the outer longitudinal muscle layer. ${ }^{2}$

The mitochondrial myopathies encompass a distinct group of well described neurological syndromes (Kearns-Sayre, myoclonic epilepsy lactic acidosis and stroke-like syndromes (MELAS), myoclonic epilepsy and ragged red fibres (MERRF), and Leber's hereditary optic neuropathy) characterised histologically by the presence of coarse subsarcolemmal red staining aggregates in skeletal muscle, stained according to the modified Gomori trichrome method. ${ }^{3}$ Expression of these syndromes frequently reflects impaired mitochondrial function consequent to mitochondrial DNA (mtDNA) changes, ${ }^{+}$most commonly deletions within the region spanning nucleotide bases $8000-9500 .^{5}$ Because mitochondria are acquired from the ova, mitochondrial myopathies are generally maternally transmitted. ${ }^{6}$

Individuals affected by either familial visceral myopathy $^{7}$ or a mitochondrial myopathy ${ }^{89}$ manifest varying degrees of intestinal pseudoobstruction, polyneuropathy, leukoencephalopathy, lactic acidosis, and ophthalmoplegia. The nearly identical clinical features have prompted previous suggestions of an association between these two disorders. ${ }^{10-12}$ We describe a 27 year old man with an undifferentiated myopathy. Histological examination of biopsy specimens and

molecular analysis show that this patient had both familial visceral myopathy and a mitochondrial myopathy, suggesting that a mtDNA lesion is associated with familial visceral myopathy.

\section{Methods}

PROBAND

A 27 year old, non-smoking, heterosexual Yugoslavian man presented with perforated duodenal diverticula. His past medical history included 10 years of diarrhoea alternating with constipation, intermittent abdominal cramps, inability to maintain weight, and a recent onset of muscle weakness with paraesthesia in all limbs. He also complained of difficulty with concentration. He was using no medications. His younger brother had nearly identical complaints and two sisters had died in infancy from unknown causes (Fig 1). Physical examination showed that the patient had a profound loss of body fat and muscle mass. His height, weight, and body mass index were $178 \mathrm{~cm}, 48 \mathrm{~kg}$, and $15 \cdot 1 \mathrm{~kg} / \mathrm{m}^{2}$, respectively. Abdominal examination showed an acute abdomen without organomegaly; stools were positive for occult blood. Neurological examination showed deficits in attention and concentration. There was moderate ophthalmoparesis on upward gaze and mild bilateral weakness in flexion and extension of muscle groups in the legs. Proprioception, vibration sense, and light touch were impaired in the legs. Cerebellar function and gait were normal.

The patient had a partial duodenal resection and a primary reanastomosis. He received total parenteral nutrition (TPN) postoperatively.

\section{PATHOLOGY STUDIES}

The duodenal tissue obtained at surgery was fixed and stained with haematoxylin and eosin. A gracilis muscle biopsy was examined with paraffin histology, a Gomori trichrome stain, and by electron microscopy.

\section{MOLECULAR STUDIES}

Total cellular DNA was extracted from $500 \mathrm{mg}$ of frozen skeletal muscle using an established procedure. ${ }^{13}$ Mitochondrial DNA spanning the region of 8530-9110 nucleotides was amplified using the Taq polymerase chain reaction (PCR). Total cellular DNA $(10 \mu \mathrm{g})$ was incubated in a Tempcycler (Coy) with Taq polymerase

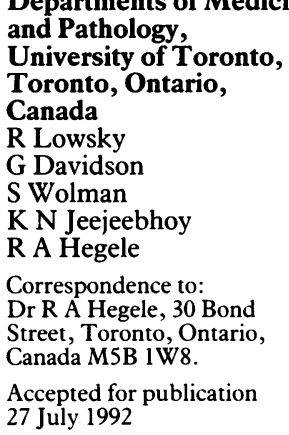


Family pedigree

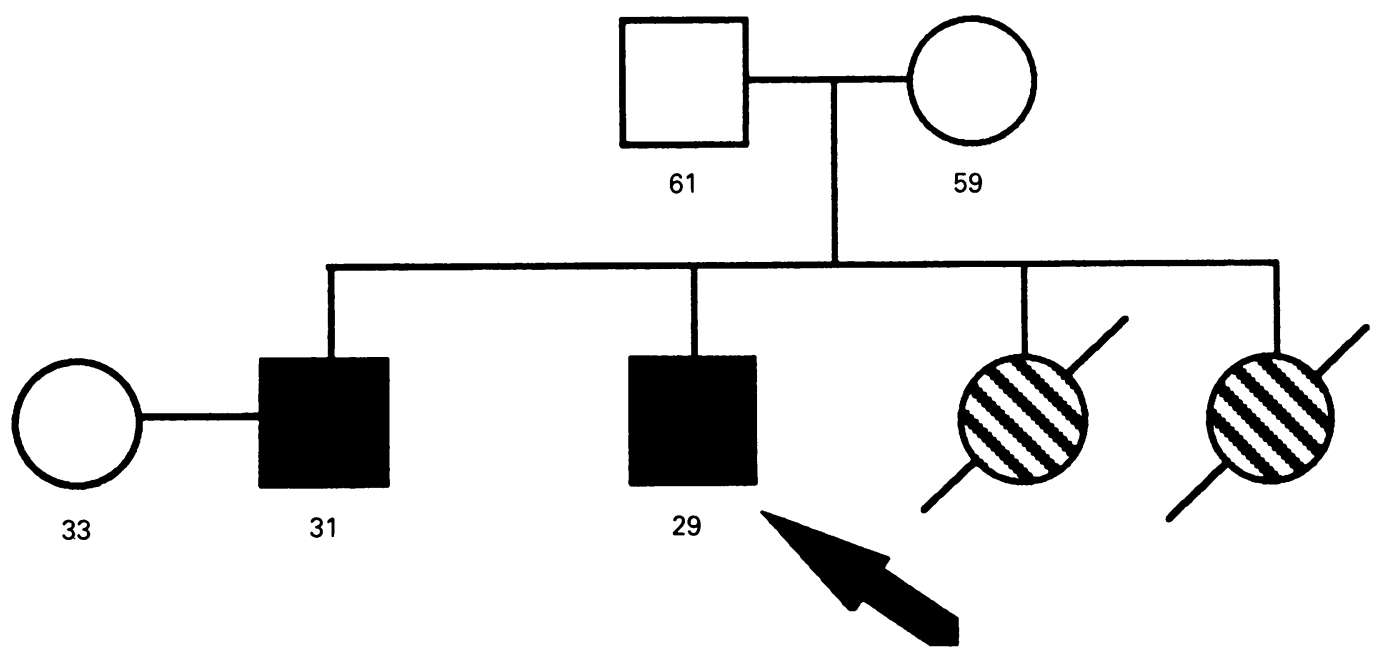

Figure 1: Pedigree structure showing first degree relatives. Closed symbols represent affected subjects, hatched symbols clinically suspect subjects, and open symbols unaffected subjects. The proband is depicted by the arrow.

(BRL) and the oligonucleotide primers 5'-ACGAAAATCTGTTCGCTTCA-3' (spanning mtDNA nucleotides 8530-8550) and 5'-ATTGTGAAGATGATAAGTGT-3' (spanning mtDNA nucleotides 9090-9110). ${ }^{14}$ The target domain was amplified in 30 three-step cycles: denaturing at $94^{\circ} \mathrm{C}$ for 90 seconds, annealing at $55^{\circ} \mathrm{C}$ for 90 seconds, and extension at $72^{\circ} \mathrm{C}$ for 240 seconds. The amplified product was then used as a probe for Southern blot analysis and as a template for nucleotide sequence analysis. Total cellular DNA was digested with endonuclease BamHI, EcoRI, or HindIII. Southern analysis was performed as described ${ }^{13}$ using the PCR amplified mtDNA product labelled with the PhotoGene Nucleic Acid Detection System (BRL) as a probe. The PCR amplified mtDNA product from the proband and a control were sequenced directly using the PCR oligonucleotide primers in dideoxy sequencing.

\section{Results}

CLINICAL FEATURES

The patient's abnormalities are given in the Table. The most important were intestinal pseudo-obstruction, polyneuropathy, leuko-

Clinical abnormalities found in a patient with familial visceral myopathy and a mitochondrial myopathy

\begin{tabular}{|c|c|c|}
\hline Laboratory test & Finding & Interpretation \\
\hline \multicolumn{3}{|l|}{ Barium studies: } \\
\hline Upper gastrointestinal & $\begin{array}{l}\text { Normal oesophagus, mild dilatation of stomach, } \\
\text { multiple diverticula within small bowel with } \\
\text { stasis of contrast material }\end{array}$ & $\begin{array}{l}\text { Intestinal pseudo- } \\
\text { obstruction }\end{array}$ \\
\hline Lower gastrointestinal & Few colonic diverticula with dilatation & \\
\hline $\begin{array}{l}\text { Nerve conduction } \\
\text { studies }\end{array}$ & $\begin{array}{l}\text { Marked delay/absence of nerve conduction in } \\
\text { upper and lower limbs }\end{array}$ & $\begin{array}{l}\text { Chronic } \\
\text { demyelinating } \\
\text { neuropathy }\end{array}$ \\
\hline $\begin{array}{l}\text { Magnetic resonance } \\
\text { imaging of cranium }\end{array}$ & Diffuse white matter lesions & Leukoencephalopathy \\
\hline $\begin{array}{l}\text { Serum lactate } \\
\text { Fasting RQ }\end{array}$ & $\begin{array}{l}>3.5 \mathrm{mmol} / \mathrm{l} \\
>1\end{array}$ & $\begin{array}{l}\text { Chronic lactic acidosis } \\
\text { Incompetent fat/lipid } \\
\text { metabolism }\end{array}$ \\
\hline $\begin{array}{l}\text { Total parenteral } \\
\text { nutrition feeding }\end{array}$ & $\begin{array}{l}\text { Milky serum, cholesterol }>18 \mathrm{mmol} / \mathrm{l} \text {, } \\
\text { triglycerides }>15 \mathrm{mmol} / \mathrm{l} \text {, no weight gain after } \\
3 \text { months }\end{array}$ & $\begin{array}{l}\text { Total parenteral } \\
\text { nutrition induced } \\
\text { hyperlipidaemia }\end{array}$ \\
\hline
\end{tabular}

encephalopathy, and many metabolic abnormalities that included a chronic lactic acidosis, total parenteral nutrition induced hyperlipidaemia, and a fasting respiratory quotient exceeding $1 \cdot 0$. The serum concentration of carnitine and the carnitine palymitol transferase activity were normal. A normal glucose response to fasting was observed (data not shown). Investigations of the proband's brother were similar, with the exceptions of the absence of total parenteral nutrition induced metabolic disturbances and the presence of type II diabetes mellitus.

\section{PATHOLOGY}

The surgical duodenal specimen from the proband showed mild villous blunting and a slightly increased cellularity of the lamina propria. There was smooth muscle cell loss with fibrosis, especially within the outer longitudinal muscle layer (Fig 2A). The myenteric plexus was unremarkable, containing numerous and normal ganglion cells. Electron microscopy examination confirmed myocyte loss and the presence of collagen fibrosis (Fig 2B). In clinical terms, these histological findings established a diagnosis of familial visceral myopathy.

The gracilis muscle biopsy showed scattered degenerating and regenerating fibres with no inflammation, fibrosis, or neurogenic changes. The Gomori trichrome stained sections showed subsarcolemmal aggregates of red granular material corresponding to abnormal mitochondria (not shown). Electron microscopy showed aggregates of mitochondria with intramitochondrial inclusions consisting of closely apposed parallel membranes resembling 'zippers' or 'parking lots' (Fig 3). These skeletal muscle fibre changes were considered pathognomonic of a mitochondrial myopathy.

\section{MOLECULAR ANALYSES}

Southern blot analysis of BamHI, EcoRI, and HindIII digested muscle DNA from our patient, hybridised with a labelled mtDNA probe, 

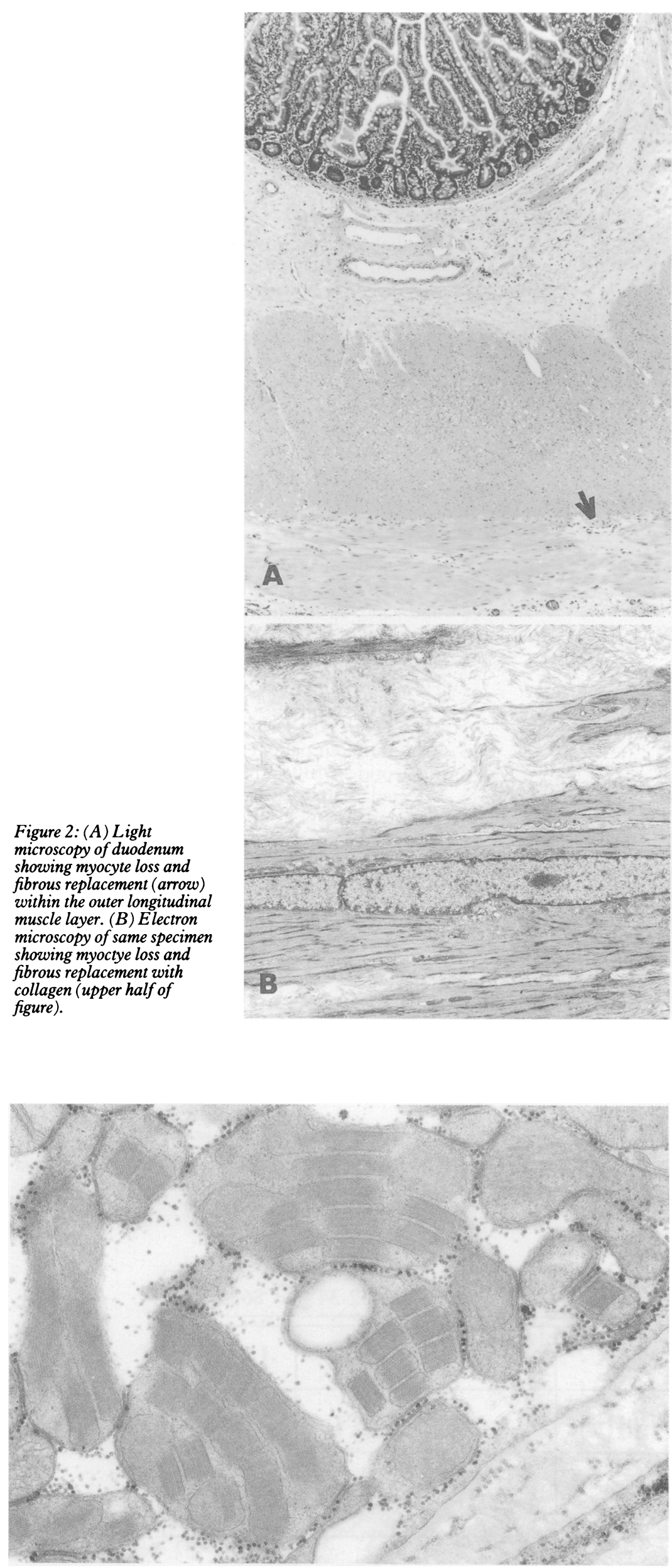

Figure 3: Electron microscopy of gracilis muscle biopsy tissue showing an aggregate of mitochondria containing 'parking lot' inclusions.

showed fragments of predicted size when compared with a normal control (Fig 4): No heterogeneity of mtDNA species (heteroplasmy) was found.

The nucleotide sequence of the mtDNA domain 8530-9110 nucleotides (a region that encodes subunit 6 of ATPase) from the proband was identical to the wild type sequence, except for a single base substitution of a thymidine for cytosine at position 8634 (Fig 5). This substitution was silent at the protein level: a tyrosine residue was translated both from the patient and the wild type mtDNA.

\section{Discussion}

We present a patient with the concomitant diagnoses of familial visceral myopathy and a mitochondrial myopathy. The diagnosis of familial visceral myopathy was based on characteristic clinical features and histological abnormalities within the small bowel. The diagnosis of a mitochondrial myopathy was based on the pathognomonic findings within the mitochondria of skeletal muscle cells when examined by Gomori trichrome and electron microscopy. The findings in this patient suggest that familial visceral myopathy and mitochondrial myopathies may have a similar molecular origin and could represent two points on the spectrum of a single disease.

Familial visceral myopathy and the mitochondrial myopathies have been distinguished from each other on the basis of muscle type affected. Familial visceral myopathy has been associated with smooth muscle cell abnormalities, whereas the mitochondrial myopathies have been characterised by skeletal muscle cell abnormalities. None of the reported cases of familial visceral myopathy, however, have undergone a Gomori trichrome stained muscle biopsy. ${ }^{2} 7^{15-22}$ Likewise, none of the reported cases of mitochondrial myopathies, specifically those in which patients were predominantly affected with a chronic intestinal pseudoobstruction, have reported the histological findings of the small bowel wall. ${ }^{9}$ It is thus possible that the failure to detect coexistent abnormalities in these conditions is the result of a lack of specific histological examination.

There are similarities in the expression of the clinical phenotypes of familial visceral myopathy and of the mitochondrial myopathies. For example, intestinal diverticulosis is a characteristic accompaniment of familial visceral myopathy and has also been described in the mitochondrial myopathies. ${ }^{9}$ Furthermore, extraintestinal neurological manifestations in familial visceral myopathy include ophthalmoplegia, megacystis, dementia, and seizure disorders, ${ }^{2192022}$ features that are also characteristic of mitochondrial disorders. In addition, a patient with familial visceral myopathy had lactic acidosis, total parenteral nutrition induced hyperlipidaemia, right bundle branch block, polyneuropathy, and leukoencephalopathy, features that are characteristic of mitochondrial disorders. Our patient had many of these clinical features.

A factor that could theoretically distinguish 


\section{$123 \quad 345$}

$16 \cdot 5 \mathrm{~kb}$ between familial visceral myopathy and the mitochondrial myopathies is their mode of inheritance. Familial visceral myopathy is inherited as an autosomal trait,' whereas the mitochondrial myopathies classically display a maternal inheritance. ${ }^{23}$ Our patient had an affected male sibling and two female siblings who had both died in infancy, suggesting autosomal dominant inheritance with variable penetrance. This would be compatible with familial visceral myopathy but not with the classical mitochondrial myopathies. However, three pedigrees with mitochondrial myopathies have been reported in which defective paternal genes affecting nuclear control over mtDNA replication resulted in large scale mtDNA deletions..$^{2+}$ Another study has shown paternal transmission of mtDNA from males in backcrossed mice. ${ }^{25}$ Thus, the mode of transmission does not necessarily distinguish familial visceral myopathy from a mitochondrial myopathy.

The genetic defect in familial visceral myopathy is unknown. In contrast, $40 \%$ of patients with mitochondrial myopathies have large scale deletions in muscle mtDNA usually including the region between nucleotides 8000 and 9500 . In addition, one form of MERRF and one form of Leber's hereditary optic neuropathy are caused by point mutations within the mitochondrial genome. ${ }^{26}{ }^{27}$ Our patient had no gross structural changes of the muscle mtDNA genome. Furthermore, detailed sequence analysis of our patient's muscle mtDNA between nucleotides 8530 and 9110 , a region that is often affected in mitochondrial myopathies, showed only a silent DNA polymorphism. The molecular defect in our patient remains to be determined. It is still possible that a single lesion affecting the mtDNA genome is responsible. The finding of

Figure 4: Southern analysis of muscle mitochondrial ( $m t) D N A$ from the proband and contro subject. The band sizes are shown. Lane 1 represents $m t D N A$ from the proband after digestion with BamHI. Lanes 2 and 3 compare mtDNA from a normal subject with mtDNA from the proband, respectively, after digestion with $E$ coRI. Lanes 4 and 5 compare $m$ tDNA from the normal subject with miDNA from the proband, respectively, after HindIII enzymatic digestion. Fragments of expected size were observed in each case: digestion with BamHI produced a $16 \cdot 5 \mathrm{~kb}$ fragment corresponding to the linearised, wild type mtDNA. Digestion with $E c o R I$ and HindIII produced the expected fragments of 7.3 and $5.5 \mathrm{~kb}$, respectively.

Normal mtDNA

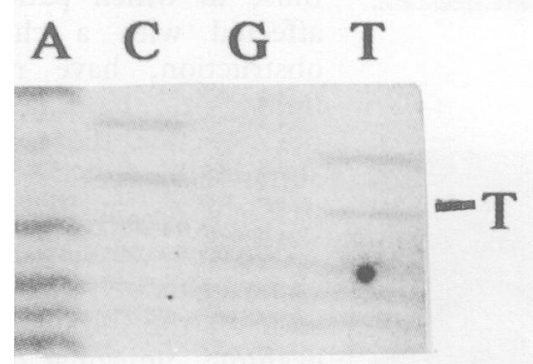

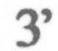

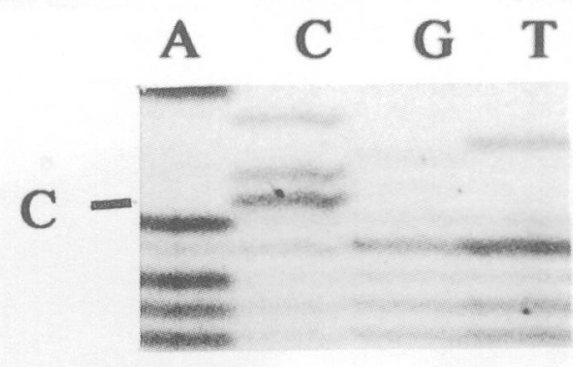

Figure 5: Direct dideoxy sequencing of muscle mitochondrial $(\mathrm{mt}) \mathrm{DNA}$ of the proband and a control subject. The reading frame is 5' to $3^{\prime}$ from bottom to top and the miDNA sequences are compared for a normal control and the proband. A single base substitution of thymine $(T)$ for cytosine $(C)$ thymine $(T)$ for cytosine $(C)$ The codons each specify tryosine.

\begin{tabular}{|c|c|c|c|}
\hline position & $8629-31$ & 8632-34 & $8635-37$ \\
\hline codon & Lys & Tyr & Leu \\
\hline normal & AAA & TAT & СTC \\
\hline patient & AAA & TAC & CTC \\
\hline & & Tyr & \\
\hline
\end{tabular}


concomitant familial visceral myopathy and mitochondrial myopathy in this family suggest that familial visceral myopathy may be a mitochondrial myopathy.

We acknowledge the assistance of Drs G Gardiner, C Bergeron, $\mathrm{K}$ Siminovitch, J Abrahamson, and L Tu. This work was supported by a grant from the Hospital for Sick Children Research Foundation

1 Anuras S, Mitros FA, Milano A, Kuminsky R, Decanio R Green JB. A familial visceral myopathy with dilatation of the entire gastrointestinal tract. Gastroenterology 1986; 90: 385-90.

2 Fitzgibbons PL, Chandrasoma PT. Familial visceral myopathy evidence of diffuse involvement of intestinal smooth muscle. Am F Surg Pathol 1987; 11: 846-54.

3 Harding AE. Neurological diseases and mitochondrial genes. Trends neurosci 1991; 14: 166-73.

4 DiMauro S. The metabolic myopathies. Curr Op in Neurol Neurosurg 1991; 4: 668-76.

5 Zeviani M, Bonilla E, DeVivo DC, DiMauro S. Mitochondrial diseases. Neurol Clin 1989; 7: 123-56.
diani M, Bonilla E, DeVivo DC, DiM

6 Harding AE, Petty RKH, Morgan-Hughes JA. Mitochondrial myopathy: a genetic study of 71 cases. $\mathcal{F}$ Med Genet 1988; 25 : 528-35.

7 Cave DR, Compton CC. A 21 -year old man with progressive gastrointestinal stasis, hepatomegaly and neurologic disorder. N Engl f Med 1990; 322: 829-41.

8 Holt IJ, Harding AE, Cooper JM, Schapira AHV, Toscano A, Clark JB, Morgan-Hughes JA. Mitochondrial myopathies: clinical and biochemical features of 30 patients with major deletions of muscle mitochondrial DNA. Ann Neurol 1989; 26: 699-708.

9 Cervera R, Bruix J, Bayes A, Illa A, Coll J, Garcia-Puges AM. Chronic intestinal pseudoobstruction and ophthalmoplegia in a patient with mitochondrial myopathy. Gut 1988; 29: in a patien.

10 Bardosi A, Creutzfeldt W, DiMauro S, Felgenhauer K, Friede RL, Goebel HH, et al. Myo-, neuro-, gastrointestinal encephalopathy (MNGIE syndrome) due to partial deficiency of cytochrome oxidase. A new mitochondrial multisystem disorder. Acta Neuropathol 1987; 74: 248-58.

11 Blake D, Lombes A, Minetti C, Bonilla E, Hays A, Lovelace RE, et al. MNGIE syndrome: report of 2 new patients. Neurologv 1990; 40 (suppl 1): 294.

12 Simon LT, Horoupian DS, Dorfman LJ, Marks M, Herrick MK, Wasserstein P, et al. Polyneuropathy, ophthal- moplegia, leucoencephalopathy and intestinal pseudoobstruction: P()LIP syndrome. Ann Neurol 1990;28. 349-60.

13 Hegele RA, Huang L, Herbert PN, Blum CB, Buring JE, Hennekens CH, et al. Apolipoprotein B-gene DNA polymorphism associated with myocardial infarction. $N$ Engly Med 1986; 315: 1509-15.

14 Anderson S, Bankier AT, Barrell MG, de Bruijn MH, Coulson $\mathrm{AR}$, Drouin J, et al. Sequence and organization of the human AR, Drouin J, et al. Sequence and organization of the

15 Anuras S, Mitros FA, Nowak TV, Ionasescu VV, Gurll NJ Christensen J, et al. A familial visceral myopathy with external ophthalmoplegia and autosomal recessive transmission. Gastroenterology 1983; 84:346-53.

16 Faber J, Fich A, Steinberg A, Steiner I, Granot E, Alon I, et al. Familial intestinal pseudoobstruction dominated by progressive neurologic disease at a young age. Gastroenterologv 1987; 92: 786-90.

17 Rodrigues CA, Shepherd NA, Lennard-Jones JE, Hawley PR Thompson HIH. Familial visceral myopathy: a family with at least six involved members. Gut 1989; 30: 1285-92.

18 Alstead EM, Murphy MN, Flanagan AM, Bishop AE, Hodgson HJF. Familial autonomic visceral myopathy with degeneration of muscularis mucosae. F Clin Pathol 1988; 41 . degenerat $42+9$.

19 Jacobs $\mathrm{F}$, Ardichvili D, Perissino A, Gottignies P, Hanssens $\mathrm{JF}$. A case of familial visceral myopathy with atrophy and fibrosis of the longitudinal muscle layer of the entire smal bowel. Gastroenterologv 1979; 77: 745-50.

20 Faulk DL, Anuras S, Gardner G, Mitros FA, Summers RW Christensen J. A familial visceral myopathy. Ann Intern Med 1978; 89: 600-6.

21 Ionasescu V, Thompson SH, Ionasescu R, Searby C, Anuras $\mathrm{S}$, Christensen J, et al. Inherited ophthalmoplegia with intestinal pseudoobstruction. F Neurol Sci 1983; 59: 215-28.

22 Schuffler MD, Pope CE. Studies of idiopathic intestinal pseudo-obstruction. Gastroenterology 1977; 73: 339-44.

23 Palca J. The other human genome. Science 1990; 249: 1104-5.

24 Zeviani M, Bresolin N, Gellera C, Bordoni A, Parmacci M, Amici G, et al. Nucleus driven multiple large scale deletions Amici G, et al. Nucleus driven multiple large scale deletions
of the human mitochondrial genome: A new autosomal of the human mitochondrial genome: A new autosom
dominant disease. Am 7 Hum Genet 1990; 47: 904-14.

25 Gyllensten U, Wharton D, Josefson A, Wilson AC. Paternal inheritance of mitochondrial DNA in mice. Nature 1991 352: $255-6$.

26 Shoffner JM, Lott MT, Iexza AM, Seibel P, Ballinger SW, Wallace DC. Myoclonic epilepsy and ragged red fibers (MERRF) is associated with a mitochondrial DNA tRNAL ys mutation. Cell 1990; 61: 931-7.

27 Wallace DC, Singh S, Lott MT, Hodge JA, Schurr TG, Lezza AMS, et al. Mitochondrial DNA mutation associated with Leber's hereditary optic neuropathy. Science 1988; 242: $1427-30$. 